\title{
Regionalized environmental impacts of construction machinery
}

\author{
Babak Ebrahimi $^{1,2}$ (D) Holger Wallbaum ${ }^{1} \cdot$ Pål Drevland Jakobsen $^{3} \cdot$ Gaylord Kabongo Booto $^{3}$
}

Received: 28 November 2018 / Accepted: 13 May 2020 / Published online: 25 June 2020

(C) The Author(s) 2020

\begin{abstract}
Purpose This study aims to establish a regionalized environmental impact assessment of construction machinery equipped with diesel engines certified by the European emission standard Stage V, and operated in cold climatic zones in Europe.

Method The study quantifies potential environmental impacts associated with construction machinery over the entire lifecycle, from extraction of materials to the end-of-life. For the operation phase, a meso-level emission accounting method is applied to quantify tailpipe emissions for certain subcategories of construction machinery. This is achieved by determining the operational efficiency of each machine in terms of effective hours. The quantified emission data are then adjusted based on engine deterioration models to estimate the rate of increase in emissions throughout the lifetime of each machine. Finally, the CML impact assessment method is applied to inventory data to quantify potential environmental impacts.

Results The study shows that tailpipe emissions, which largely depend on an engine's fuel consumption, had the largest contribution to environmental impacts in most impact categories. At the same time, there was a positive correlation between the operation weight and the impacts of the machinery. Also, machinery with similar operation weight had relatively similar impact patterns due to similar driving factors and dependencies. In addition, network, sensitivity, and uncertainty analyses were performed to quantify the source of impacts and validate the robustness of the study. Results of the sensitivity analysis showed that the responsiveness of the studied systems is very sensitive to changes in the amount of fuel consumption. In addition, the uncertainty results showed that the domain of uncertainty increased as the operation weight subcategory of machinery increased. Conclusion This study extends previous work on the life cycle assessment (LCA) of construction machinery, and the methodology developed provides a basis for future extension and improvement in this field. The use of effective hours as the unit of operational efficiency helps to resolve uncertainties linked to lifetime and annual operation hours. Also, the obtained results can be of use for decision support and for assessing the impacts of transition from fossil fuels to alternative fuel types.
\end{abstract}

Keywords Life cycle assessment $\cdot$ Non-road mobile machinery $\cdot$ Construction machinery $\cdot$ Attributional LCA

\section{Introduction}

Responsible editor: Alexander Passer

Electronic supplementary material The online version of this article (https://doi.org/10.1007/s11367-020-01769-x) contains supplementary material, which is available to authorized users.

Babak Ebrahimi

babake@chalmers.se

1 Dept. of Architecture and Civil Engineering, Chalmers University of Technology, SE-412 96 Gothenburg, Sweden

2 Department of Environment Impacts and Sustainability, NILU Norwegian Institute for Air Research, P.O. Box 100, Kjeller 2027, Norway

3 Dept. of Civil and Environmental Engineering, Norwegian University of Science and Technology, 7491 Trondheim, Norway
In any civil engineering project, the use of machinery is an inevitable part of construction works. Construction machinery is designed to carry out various tasks and sometimes to repurpose parts of the ground. Diesel fuel has predominantly been the main source of energy for most construction machinery (Lewis and Rasdorf 2017), and as the result, different tailpipe pollutants are discharged to the air (Bruce et al. 2001). Carbon dioxide $\left(\mathrm{CO}_{2}\right)$, sulfur dioxide $\left(\mathrm{SO}_{2}\right)$, nitrogen oxides $(\mathrm{NOx})$, and particulate matter (PM) are examples of such exhaust emissions (Frey et al. 2008; Rasdorf et al. 2010; Lewis and Rasdorf 2017).

Various solutions and approaches have been suggested to reduce emissions in the construction machinery domain. These solutions have been intended to mitigate emissions and phase out the most pollinating machinery. In the past 
few decades, a series of directives have been mandated by the European Commissions to restrict tailpipe emissions from construction machinery (EC 1997, 2002, 2010). These directives have been kept up-to-date to assist Europe in achieving its mitigation goals by highlighting maximum allowed emission levels in consecutive stages, i.e., Stage I-VI standards (Nesbit et al. 2016).

Besides the European directives and the remarkable advancements in technology, it is still in the interest of many stakeholders to measure and assess their environmental performance and to clearly see how they can fulfill their environmental goals, such as reducing the carbon emissions of their operations. In order to meet a climate mitigation target in the construction sector, a combination of measures should be conducted with respect to construction machinery. This includes setting a maximum allowed idle time, changing fuel types and blends, utilizing machinery equipped with newer technology with higher emission standards, and shifting to electric powertrain systems (Frey et al. 2008; Fridstr 2013; Abbasian-hosseini et al. 2016; Weber and Amundsen 2016).

Alongside the interest in gaining insightful knowledge about the environmental impacts of construction machinery, different studies have been carried out to assess the performance of different types and subcategories of construction machinery, and in different setups (Lijewski et al. 2013; Cao et al. 2016; Lewis et al. 2017). However, most studies have only focused on the direct emissions associated with the operation phase of the studied machinery. This focus has been chosen because of the relatively high environmental impacts during this phase compared with other lifecycle phases. This is also highlighted by the low number of life cycle assessments (LCA) focusing on construction machinery (Lee et al. 2000; Athanassiadis et al. 2002; Kim et al. 2012a, b).

Having coherent insight into the operation phase of construction machinery can indisputably enhance estimations of impacts and assist in making informed decisions. In general, there are two typical approaches to estimate emissions from the operation phase of a machine and the potential subsequent environmental impacts, namely a top-down approach and a bottom-up approach. The topdown approach simply requires two types of input data to estimate the emissions: (1) the amount and type of sold/ consumed fuel and (2) a representative emission factor for each fuel type. Several studies have used this approach (e.g., Kasibhatla et al., 2002; Wetterberg et al., 2007; Becken and Patterson, 2009; Helms and Lambrecht 2009; Guan et al., 2012). Due to the simplicity of this approach, the generated results are often very coarse and lack detailed information. Specifically, the results attained using a top-down approach often struggle to explain the conditions under which each subcategory of machinery are operated.
In comparison, a bottom-up approach requires additional fundamental information to estimate the performance of a machine. This may include engine speed, operation hours, torque or power, weight of machinery, engine type, fuel type, and lifetime of the equipment (Smith et al. 2000; Bruce et al. 2001; Lindgren 2005; Frey et al. 2008; Ahn et al. 2013). In addition, there are other external parameters that explain the underlying performance of machinery, including the climatic and ground conditions, experience of drivers, land types, angle of terrain, and the density and volume of sediments being worked. While creating a bottom-up approach would increase precisions in the estimation of machinery performance during operation, this requires large sample datasets that cover all variables in order to obtain a realistic picture of the whole system.

In addition to the top-down and bottom-up approaches, a third approach has become more popular in the scientific literature (Lewis et al. 2009; Hajji and Lewis 2013; Fan 2017). This "meso-level analysis" stands somewhere in between the top-down and bottom-up approaches. The meso-level analytical approach overcomes the limitations in the alternative approaches and capitalizes on their merits. In other words, the meso-level approach dealing with a medium-size system (groups of construction machinery) and explains performance within each group. Medium in a sense that the system is not bounded to individual construction machinery, as it is for a small system dealing with individual machinery, and nor to entire construction fleet (i.e., a broad system with a high level of aggregation missing resolutions). Specifically, the mesolevel approach is faster to apply than the bottom-up approach, yet is more detailed than the top-down approach. It often uses historical data combined with complementary information to estimate emissions. Such data often contain information that can help characterize the conditions under which a task was conducted, the productivity of the machine, and its operational lifetime.

This study expands the existing research on the LCA of construction machinery equipped with diesel engines. In doing so, the regionalized LCA of construction machinery was conducted and supplemented using meso-level analysis to quantify emissions associated with the operation phase of machinery in cold regions in Europe. Statistical information for subcategories of construction machinery operated in Norway is used to quantify overall impact. A life cycle inventory (LCI) for each subcategory is created following the "cradle-tograve" approach, corresponding to stages $\mathrm{A}$ to $\mathrm{C}$ in the European Standard EN 15978:2011 (CEN/TC 350 2011). It was necessary to consider these lifecycle stages because of continuous advancements in the LCA databases (Steubing et al. 2016; Wernet et al. 2016), which could subsequently influence the relative impact among different stages. In addition, this study uses time-varying emission factors to calculate operational emissions over the lifetime of each subcategory of machinery. These time-varying emission factors show the 
effect of engine deterioration and are quantified by fitting them to logistic distribution models. Finally, the network, sensitivity, and uncertainty of the LCA study are assessed to evaluate the root causes of impacts, and the robustness and reliability of the results.

\section{Methodology}

\subsection{Goal, scope, and data sources}

The goal of this study was to establish a regionalized attributional LCA to quantify the environmental impacts associated with construction machinery equipped with diesel engines (certified by the European emission standard Stage V) over their entire lifecycle, i.e., from cradleto-grave. The outcomes of this are considered relevant for decision-makers and LCA practitioners who would like to apply the results or the method for further development, including comparative studies and ranking different construction machinery, and including other environmental contexts.

The scope was limited to selected subcategories of construction machinery operated in Norway. The study focused on five types of construction machinery in different subcategories. The information related to the machinery was sourced from the Norwegian construction machinery database (NTNU and MEF 2016), which includes a representative performance for each subcategory. The database covers a range of historical data, dating back to the 1970 s, from various construction projects in Norway.
The functional unit was one construction machine operated throughout its expected economic lifetime. The economic lifetime for each machine was measured using the unit "effective hour" (EH; see Table 1). An effective hour is a time that a machine operates efficiently, accounting for both direct and indirect productive time necessary to perform the required duties (Aune et al. 1992).

The condition under which a machine operates often influences fuel consumption and, subsequently, tailpipe emissions. In this study, medium operation conditions were assumed for most of construction machinery listed in Table 1 . In the case of wheel loaders, these were operated in well-designed and welloperated rock quarries to move blasted rock materials with a d50 of 200-250 $\mathrm{mm}$.

The impact assessment in this study used the CML impact assessment method version 4.2 (Pre' 2018), which is also recommended in European Standard 15804 for the sustainability assessment of construction work (CEN, 2013). The following impact categories were assessed in this study: abiotic depletion (AD, $\mathrm{kg}$ Sb eq.); fossil fuelbased abiotic depletion (ADP, MJ); acidification (AP, kg $\mathrm{SO} 2$ eq.); eutrophication (EP, kg PO4- eq.); freshwater aquatic ecotoxicity (FE, kg 1.4-DB eq.); global warming (GWP, kg CO2 eq.); human toxicity (HT, kg 1.4-DB eq.); marine aquatic ecotoxicity (ME, $\mathrm{kg}$ 1.4-DB eq.); ozone layer depletion (ODP, kg CFC-11 eq.); photochemical oxidation (PO, kg C2H4 eq.); and terrestrial ecotoxicity (TE, kg 1.4-DB eq.).

The LCA analysis in this study was performed using SimaPro v8.4 (SimaPro 2017) and ecoinvent database version 3.3 (ecoinvent 2016). In addition to the ecoinvent database, other sources of information were used to modify standard

Table 1 Summary of studied construction machinery

\begin{tabular}{|c|c|c|c|c|c|c|c|}
\hline Machine type & $\begin{array}{l}\text { Engine net power } \\
(\mathrm{kW})\end{array}$ & $\begin{array}{l}\text { Operating weight } \\
\text { (ton) }\end{array}$ & $\begin{array}{l}\text { Economic lifetime } \\
\text { (EH) }\end{array}$ & $\begin{array}{l}\text { No. of } \\
\text { tires }\end{array}$ & $\begin{array}{l}\text { Lifetime of } \\
\text { tire }\end{array}$ & $\begin{array}{l}\text { Fuel efficiency } \\
(1 / E H)\end{array}$ & $\begin{array}{l}\text { Abbreviation of } \\
\text { machine }\end{array}$ \\
\hline \multirow{2}{*}{$\begin{array}{l}\text { Articulated } \\
\text { hauler }\end{array}$} & 220 & 20 & 9000 & 6 & 1700 & 30 & $\mathrm{AH} 20$ \\
\hline & 330 & 30 & 11,000 & 6 & 1900 & 42 & АH30 \\
\hline \multirow{5}{*}{$\begin{array}{l}\text { Crawler } \\
\text { excavator }\end{array}$} & 75 & 16 & 10,000 & - & - & 16 & CE16 \\
\hline & 120 & 22 & 10,500 & - & - & 22 & CE22 \\
\hline & 120 & 23 & 10,600 & - & - & 24 & CE23 \\
\hline & 150 & 31 & 11,600 & - & - & 31 & CE31 \\
\hline & 260 & 48 & 12,000 & - & - & 51 & CE48 \\
\hline Grader & 160 & 20 & 9300 & 6 & 780 & 25 & G20 \\
\hline \multirow{2}{*}{$\begin{array}{l}\text { Wheel } \\
\text { excavator }\end{array}$} & 87 & 14 & 9500 & 8 & $1300^{\mathrm{a}}$ & 15 & WE14 \\
\hline & 110 & 20 & 10,000 & 8 & $1500^{\mathrm{a}}$ & 20 & WE20 \\
\hline \multirow[t]{4}{*}{ Wheel loader } & 140 & 16 & 8300 & 4 & 1650 & 23 & WL16 \\
\hline & 180 & 21 & 8400 & 4 & 1700 & 30 & WL21 \\
\hline & 200 & 23 & 9200 & 4 & 1800 & 36 & WL23 \\
\hline & 260 & 30 & 9800 & 4 & 2075 & 46 & WL30 \\
\hline
\end{tabular}

${ }^{\text {a Assumptions }}$ 
Table 2 Boundary of the studied system and the data source

\begin{tabular}{ll}
\hline Life cycle stage & Data source \\
\hline Manufacturing and material inputs & ecoinvent v3.3 \\
& Volvo EPD documents (Volvoce 2018) \\
& LCI process for production of tires (Krömer et al. 1999; UNEP 2011) \\
Eperation & EMEP/EEA guidebooks (Winther et al. 2013, 2017) \\
& ecoinvent v3.3 \\
Maintenance & Operation of construction machinery (see Table 1) \\
& EMEP/EEA guidebooks (Winther et al. 2013, 2017) \\
End-of-life & ecoinvent v3.3 \\
& Service manual (Caterpillar 2010, 2011, 2012; Johan Deere 2012) \\
\hline
\end{tabular}

LCI processes, like emission modelling, reference to relevant reports, and other literature including environmental product declaration (EPD) documents. These modifications helped to establish regionalized LCI processes for each subcategory of construction machinery. Table 2 presents an overview of the applied sources in the LCI used in this study. In the following subsections, explanations of the data sources and the applied methods are also provided.

\subsubsection{Manufacturing of machinery}

To generate regionalized LCI processes for each subcategory of machinery, the following ecoinvent processes were used:

- "Lorry, 16t metric ton $\{$ RER $\} \mid$ Alloc Def, U"

- "Lorry, 28t metric ton $\{$ RER $\} \mid$ Alloc Def, U"

- "Lorry, 40t metric ton $\{$ RER $\} \mid$ Alloc Def, U"

However, some input and output flows within each process were adjusted so that they were representative of the studied machinery. Through the course of the adjustments, effort was made to use representative information. When representative information was not available, the existing assumptions of ecoinvent were applied using on the default values. Appendix S1 represents the structure of the LCI processes for all of the construction machinery presented in Table 1 to demonstrate how the LCI processes were created, and explains the underlying assumptions.

\subsubsection{Operation of machinery}

The information shown in Table 1 was coupled with certain emission factors and other supplementary materials to estimate tailpipe emissions. The European emissions inventory guidebook (hereafter referred to as the EMEP/EEA guidebook) was used, as it states baseline emission factors. The EMEP/EEA guidebook is the result of a joint effort by the European Environmental Agency (EEA) and the European
Monitoring and Evaluation Programme (EMEP) (Winther et al. 2017).

As information related to the engine size for the machinery was known, estimation of emissions was based on Tier 3 methodology as developed in the EMEP/EEA guidebook. In addition, selected information from the EMEP/EEA guidebook (Winther et al. 2017) was limited to one emission standard (i.e., Stage $\mathrm{V}$ emission standards), and the power ranges 75-130 kW and 130-560 kW. Equation 1 was used to quantify emissions associated with each subcategory of machinery. The equation was primarily based on proposed formula in the EMEP/EEA guidebook; however, it was adjusted to fit to the data in this study.

$E_{x i}=\sum_{t=0}^{E H} B E F_{t p i} \cdot F C_{x} \cdot E D_{x y} \cdot L F_{t} \cdot\left(1+A D F_{t p i}\right)$

where $E$ is the calculated amount of pollutant for construction machinery $x$ in units of mass $(\mathrm{g}) ; B E F$ is the baseline emission factor of pollutant $i$ for the power range $p$ and technology level $t$ in units of mass per energy (g/kWh); $F C$ is fuel efficiency of machinery $x$ in units of liter per effective hour (1/eh); ED is energy density of fuel $y$ burned in machinery $x$ ( $\mathrm{g} / \mathrm{kg}$ fuel); $L F$ is the adjustment load factor as a function of technology levels $t$ and is the portion of engine power utilized during operating conditions (this was set to 100\%) (\%); and $A D F$ is the adjusted deterioration factor which modifies emissions as the machinery ages (\%).

Equation 1 was used to quantify emissions over the economic lifetime of construction machinery $x . B E F$ is a function of technology levels $t$ and power ranges $p(\mathrm{kWh})$ and Table 3 presents the baseline emission factors for the studied machinery.

$\mathrm{CO}_{2}$ and $\mathrm{SO}_{2}$ were predominantly assumed as fueldriven emissions rather than depending on engine type and equipment technology (Winther et al. 2017). Since no emission factor is suggested for these emissions in the EMEP/EEA guidebook (Winther et al. 2013, 2017), the $\mathrm{CO}_{2}$ intensity of fuels suggested by Lindgren (2007) 
Table 3 Baseline emission factors

\begin{tabular}{llllllllll}
\hline Engine power $(\mathrm{kW})$ & Technology level & $\mathrm{BC}$ & $\mathrm{CH}_{4}$ & $\mathrm{CO}$ & $\mathrm{NH}_{3}$ & $\mathrm{~N}_{2} \mathrm{O}$ & $\mathrm{NO}_{\mathrm{x}}$ & $\mathrm{PM}$ & $\mathrm{VOC}$ \\
\hline $75<=P<560$ & Stage V & 0.002 & 0.003 & 1.5 & 0.002 & 0.035 & 0.4 & 0.015 & 0.13 \\
\hline
\end{tabular}

was adopted, which assumed $\mathrm{CO}_{2}$ emission at a rate of $3146 \mathrm{~g} / \mathrm{kg}$ burned fuel. In addition, a maximum sulfur limit of $10 \mathrm{ppm}$ was chosen for diesel fuel (European Commission 2009) and it was assumed that all sulfur in the fuel was fully transformed to $\mathrm{SO}_{2}$. Also, it was assumed that the density of diesel was $0.85 \mathrm{~kg} / \mathrm{l}$.

As a vehicle ages, the technical capabilities of the engine deteriorate together with its overall performance. This deterioration process, also termed engine degradation behavior, usually results in increased tailpipe emissions. To account for engine degradation behavior and to produce a more reliable estimation of emissions from the machinery, logistic distribution models were applied. The models were used to derive deterioration factors for a set of air pollutants from their initial emission levels (see Table 3).

To measure the effect of engine deterioration on the tailpipe emissions, calculations were performed from time zero (i.e., the first day of operation of the machinery) to the machinery end-of-life. Three retardation factors were applied to account for the rate of deterioration (see Fig. 1). A retardation factor was a point at which the rate of deterioration was halfway between zero and the maximum-adjusted deterioration at the end-of-life. The three factors were chosen to reflect the potential range of behaviors with respect to the pace and rate of pollutant formation. The $50 \%$ retardation factor was used as the baseline for LCA analysis, while the $30 \%$ and $70 \%$ retardation factors were considered the lower and upper bounds to represent faster and slower rates of deterioration, respectively. The effects of the upper and lower bounds are examined as part of the uncertainty analyses.

To customize the demonstrated distribution in Fig. 1 for different pollutants, the $Y$-axis (i.e., rate of deterioration) was multiplied by the deterioration factor of each gas. Table 4 shows the adjusted deterioration factors for fewer pollutants than those shown in Table 3. For pollutants with no deterioration factor (i.e., black carbon, dinitrogen oxide, and ammonia), it was assumed that there would be no effect from engine deterioration. In these cases, the emission factor remained constant over the lifetimes of the machines.

\subsubsection{Maintenance of machinery}

Throughout the lifetimes of machinery, follow-up services and repairs take place to optimize performance and minimize associated maintenance costs. The LCI of the maintenance phase of machinery was structured based on the following ecoinvent processes:

- "Maintenance, lorry 16 metric ton $\{$ RoW $\} \mid$ processing $\mid$ Alloc Def, U"

- "Maintenance, lorry 28 metric ton $\{$ RoW $\} \mid$ processing | Alloc Def, U"

- "Maintenance, lorry 40 metric ton $\{$ RoW $\} \mid$ processing | Alloc Def, U"

However, adjustments were applied to make the maintenance processes more representative (see Appendix S1).

\subsubsection{End-of-life of machinery}

As with the LCI approach used for the manufacturing and maintenance of machinery, the developed ecoinvent processes were used for the end-of-life phase of machinery. The following processes were chosen for this purpose:

- Used lorry, 16 metric ton $\{\mathrm{GLO}\} \mid$ market for $\mid$ Alloc Def, U

- Used lorry, 28 metric ton $\{$ GLO $\} \mid$ market for $\mid$ Alloc Def, $U$

- Used lorry, 40 metric ton $\{\mathrm{GLO}\} \mid$ market for $\mid$ Alloc Def, $\mathrm{U}$

Fig. 1 Deterioration distribution

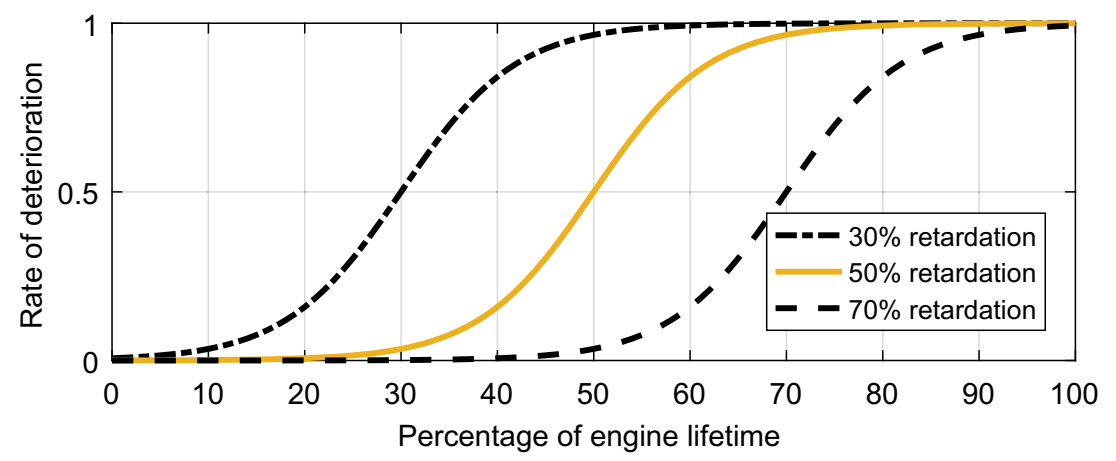


Table 4 Adjustment deterioration factor

\begin{tabular}{lllllllll}
\hline & $\mathrm{CH}_{4}$ & $\mathrm{CO}$ & $\mathrm{CO}_{2}$ & $\mathrm{FC}^{\mathrm{a}}$ & $\mathrm{NO}_{\mathrm{x}}$ & $\mathrm{PM}^{\mathrm{V}}$ & $\mathrm{VOC}$ & $\mathrm{SO}_{2}$ \\
\hline Deterioration factor (\% avg. engine lifetime) & $0.15^{\mathrm{b}}$ & $0.151^{\mathrm{c}}$ & $0.1^{\mathrm{b}}$ & $0.1^{\mathrm{b}}$ & $0.008^{\mathrm{c}}$ & $0.3^{\mathrm{b}}$ & $0.027^{\mathrm{c}}$ & $0.1^{\mathrm{b}}$ \\
\hline
\end{tabular}

${ }^{\mathrm{a}}$ Fuel consumption

${ }^{\mathrm{b}}$ Obtained from the emission inventory guidebook (Winther et al. 2013)

${ }^{\mathrm{c}}$ Obtained from the emission inventory guidebook (Winther et al. 2017)

Similarly, each ecoinvent process was modified for the end-of-life phase of machinery (see Appendix S1).

\section{Results}

Figure 2 demonstrates a comparative assessment of environmental impacts associated with each subcategory of construction machinery. The normalized impacts for machinery are shown in each corresponding impact category. Since there are not any technological differences and all machinery is equipped with diesel-based combustion engines, only one type of machinery was found to have high impacts in all the impact categories. In other words, CE48 was the most environmentally intensive machine in all impact categories and, therefore, the impacts from other types of construction machinery are relatively small in comparison. The quantitative values in Fig. 2 are provided in the supplementary data (S2).
Figure 2 also demonstrates the proportion of impacts from different sources over the lifetimes of the machinery. As can be seen, diesel-which is the assumed energy source for all the machinery - is predominantly the main (and sometimes major) contributor in seven impact categories (ADP_F, AP, EP, HT, ME, ODP, and TE). These high impacts are primarily due to the production of low-sulfur diesel throughout the value chain, which results in diverse impacts from upstream sources. Despite the relatively high impacts, diesel still contributes to the remaining impact categories, but with marginal proportions. In comparison, the tailpipe impacts from the combustion of diesel fuel during the operation phase dominate the results for the GWP and PO impact categories.

The manufacturing phase, which is the assembly line and distribution of the machinery, was shown to be the least influential phase in all impact categories. This phase was limited to three main contributors: (1) energy consumption in form of heat and electricity during the manufacturing activities, (2) diesel consumption and emitted tailpipe gases due to engine

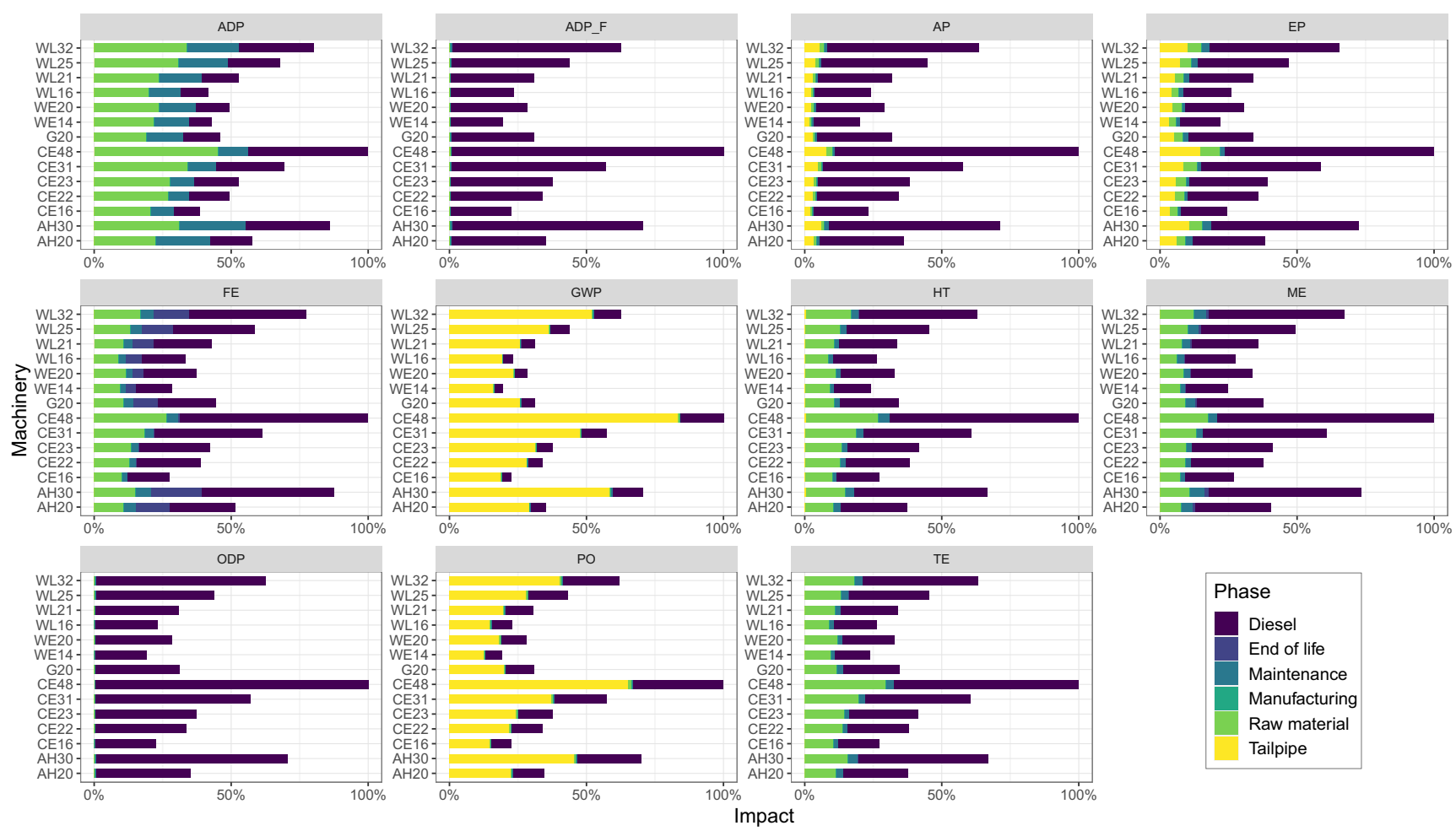

Fig. 2 Normalized impact assessment of results 
test, and (3) wastewater produced during the manufacturing. In comparison, the base material, which is the input to the manufacturing phase, had different environmental burdens, and the proportion of their contributions are shown in the categories ADP, FE, HT, ME, and TE. The base material consists of all processes from material extraction and production to the fabrication of components, which are later used as the inputs to the manufacturing phase. However, the main contributors among the inputs characterized as the base material are from iron-based products, cables, tires, and batteries. The maintenance and end-of-life phases of machinery had minor contributions across all impact categories, except for $\mathrm{ADP}$ and FE, respectively. In the case of ADP, the considerable impact share from the maintenance phase results from the environmental burdens associated with materials during the replacement of parts such as tires, batteries, lubricants, and mechanical parts. However, the use of waste tires as the fuel source in cement production explains the contribution of the end-of-life phase in the FE impact category.

The result table of the foreground system for each construction machinery can found in Appendix S3.

\subsection{Network analysis of potential impacts}

Because of the interconnectivities between processes in the ecoinvent database, it was possible to perform a network analysis to understand linkages and latent causes of LCI processes and impacts. The network analysis was performed on using SimaPro software to assess the root cause of impacts from both the dominant LCI processes and the emitted substances. Appendix S4 shows the top-ranking LCI processes responsible for each machinery type and in each impact category.

The impacts of abiotic depletion (ADP) were dominated by lead, zinc, and copper mining operations, as well as syntactic rubber and gold production. These were the top-ranking background processes responsible for ADP impacts, associated with the base materials prior to manufacturing of the machinery such as the production of batteries, tires, and electronic devices. Unlike the other impact categories, and with the exception of ADP_F, ADP impact was not caused by the emission of pollutants. Instead, these impacts were measured as the amount of used raw materials transformed from their natural state. Likewise, fossil fuel-based abiotic depletion (ADP F) was predominantly (ca. 98\%) initiated by the on-shore production of petroleum, with small contributions from the burning of sweet gas (1\%) and waste natural gas (1\%) in the fossil fuel-refining process.

Acidification potential (AP) was influenced primarily by waste natural gas and heat fuel oil during the refinery processing of fossil fuel. The freight transport of goods by transoceanic tankers and the combustion of diesel fuel by construction machinery (with $10 \mathrm{ppm}$ sulfur) were the other contributing LCI processes in the AP category. Airborne emissions from these processes resulted from $\mathrm{SO} 2$, and to the lesser degree, NOx.

The disposal of spoils from lignite and coal mining, onshore production of petroleum, and combustion of diesel by construction machinery contributed to eutrophication potential (EP). Infiltration of phosphate and oxidizable pollutants into water bodies and the airborne emission of NOx were the substances causing these impacts.

Freshwater aquatic ecotoxicity (FE) was mainly dominated by the disposal of spoil from lignite and hard coal mining, water discharge from the oil industry, and the incineration of scrap steel. Utilization of lignite and coal (as energy sources for on-shore well operation and pig iron production) results in the infiltration of spoil into water (Doka 2009). The assumed waste treatment scenario for the used tires triggers impacts associated with the incineration of scrap steel. Waste tires containing steel wires in their structures were assumed to be incinerated as the fuel source in cement production. Mining, discharge, and incineration results in heavy metal leachates reaching water bodies, including nickel, copper, beryllium, barium, vanadium, and zinc.

The direct and indirect emission of $\mathrm{CO} 2$ was the dominant causes of global warming potential (GWP) impact. This substance is formed during the combustion of diesel fuel (by the machinery) and the upstream processes related to the production of the consumed diesel.

Human toxicity (HT) was related to the production of ferrochromium as the input to low-alloyed steel production, the discharge of treated water, and the combustion of heavy fuel oil by the oil industry prior to the production of diesel fuel. Hazardous emissions, like chromium VI, nickel, benzene, cadmium, and hydrogen fluoride, were the major airborne substances contributing to the HT impact.

Marine aquatic ecotoxicity (ME) was dominated by impacts from the disposal of spoil from lignite and hard coal mining, water discharge from the oil industry, and sulfidic tailing from copper mining. These supply chain processes involve in the discharge of toxic pollutants to air, water, and soil.

Like ADP_F, the source of impacts for the ozone depletion (ODP) was linked to diesel fuel production. However, the underlying driver of this impact was related to the discharge of reactive air pollutants that degrade the ozone layer, like bromotrifluoromethane, 1,2-dichlorotetrafluoroethane, and chlorodifluoromethane.

Photochemical oxidation (PO) had somewhat similar underlying causes in GWP impact. The dominant processes in this regard were direct emission from the combustion of diesel, the diesel production supply chain, and the discharge of waste natural gas during petroleum refinement. Carbon monoxide, sulfur dioxide, pentane, and butane were the leading airborne substances contributing to the PO impact. 
Terrestrial ecotoxicity (TE) was influenced by the supply chain processes and the release of heavy metal substances. Drilling waste during the excavation of reservoirs, emission of waste natural gas, and the combustion of refinery gas (as the background processes prior to the production of diesel), as well as production processes related to low-alloyed steel and cast iron, constituted $40 \%$ of the supply chain-related impacts in the TE category.

\subsection{Sensitivity analysis}

Based on the results obtained from the network analysis, it was identified that diesel fuel, ferro materials, tires, and lead were the impactful inputs in some of the impact categories. A series of sensitivity analyses were therefore performed to examine the responsiveness of the studied system to changes in these inputs. Figure 3 illustrates the relative changes in total impacts based on a $10 \%$ increase in each input. The comparison was made by using the baseline scenario, for which the impacts have been previously discussed, as demonstrated in Fig. 2 and Appendix S2. In addition, the sensitivity analysis was limited to the two most polluting machinery types to avoid complicating the assessment. This also included machinery types with different means of mobility, i.e., tire versus track-chain machines.

An increase in fuel consumption and a subsequent increase in tailpipe emissions had significant effects on most of the impact categories. The extent of this impact is shown in the fact that the ratio of fuel consumption to impacts increased by almost $100 \%$ for ADP_F, AP, EP, GWP, ODP, and PO.

Despite the high response rates, the sensitivity of impacts from the other LCI processes was not as significant as those resulting in fuel consumption. In fact, the system was resilient to the other adjusted processes, which did not cause a significant response. The quantitative values summarized in Fig. 3 are included in Appendix S5.

\subsection{Uncertainty analysis}

In addition to the network and sensitivity analyses, uncertainties of the single-point impact assessments needed to be evaluated to enhance the reliability of the results. For this, uncertainty analysis was based on the variability of the created LCI data, focusing solely on the total impact assessment.

In doing so, the pedigree approach was used to calculate the uncertainty of the input values in each created LCI process (Weidema et al. 2013). This was done by assigning uncertainties of input and output flows within the studied system, based on a calculation made by the pedigree matrix to quantify the quality of information. The calculation is done via six indicators to measure the quality of the information in a qualitative manner (i.e., reliability, completeness, temporal correlation, geographical correlation, further technological correlation, and sample size).

Figure 4 is based on the uncertainty analysis and depicts comparative results for each impact category. The analysis was performed within the SimaPro environment using Monte Carlo simulation and the pedigree uncertainty approach. Figure 4 shows random deviation and relative accuracy in the impact results based on 1000 iterations with a 95\% confidence interval. The numerical values summarized in Fig. 4 are also provided in Appendix S6.

Figure 4 is the integration of box plots and violin plots (i.e., kernel distribution plots) showing the overall spread of the results. By evaluating the mean and median values, it became clear that the order of impacts from the different machinery types was not changed. This meant that CE48 remained the most polluting machine, followed by $\mathrm{AH} 30$ and so on. This, to some extent, can be explained by the assumption that the uncertainty for all the machinery was identical. However, by comparing the lower and upper bounds of the boxplots (i.e., the 25th and 75th percentiles), and the standard divisions, it was no longer possible to identify with complete certainty whether one construction machine had a greater or lesser impact relative to the others. In other words, Fig. 4 shows the probability of the impacts from one machine being higher or lower than the others.

\section{Discussion}

The machinery impact assessment shows, similar to other studies (Lee et al. 2000; Athanassiadis et al. 2002; Kim et al. 2012a), that the operation phase of fossil fuel-based machinery was the dominant cause of environmental impacts. Indeed, the operation phase was sometimes the only main cause of the potential impacts. However, for some impact categories, such as $\mathrm{ADP}, \mathrm{FE}, \mathrm{HT}, \mathrm{ME}$, and TE, other phases also contributed.

Figure 2 showed strong evidence of the relative impacts in each category of machinery with respect to their operational weight. This indicates that the heavier a machine is, the more environmental impacts it will have over its entire lifecycle (NB. It is worthwhile to remember that "the heavier, the more environmental impacts" statement compares only construction machinery belonging to the same category and performing under similar operating condition.) This is predominantly because of the higher fuel consumption associated with heavier machinery, especially when performing more difficult tasks. However, the proportion of impacts caused by the production and consumption of diesel fuel was dependent on machine lifetime, fuel efficiency, and operational efficiency.

Although environmental impacts during the end-of-life phase of machinery have been considered to be relatively insignificant relative to other phases (Lee et al. 2000; Kim 


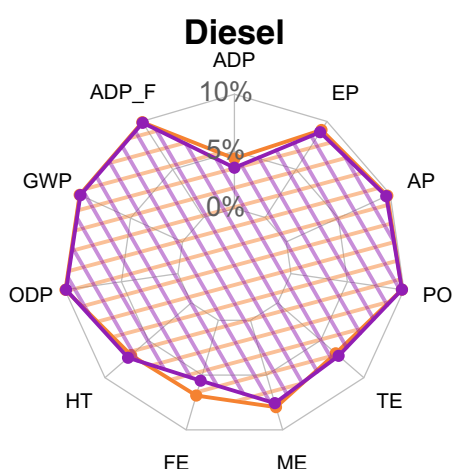

FE $\quad$ ME

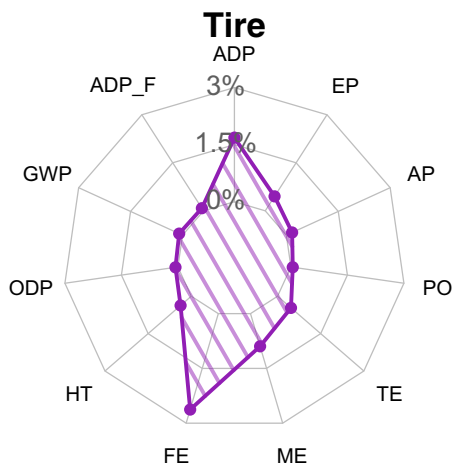

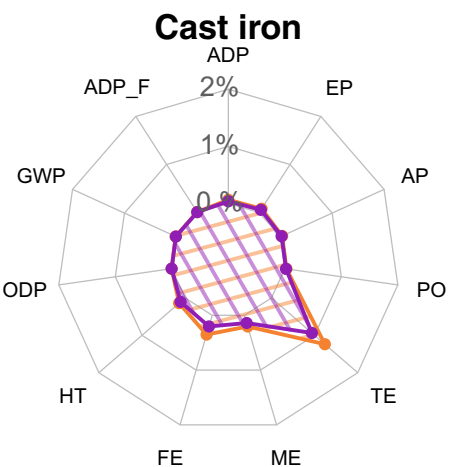

FE $\quad$ ME

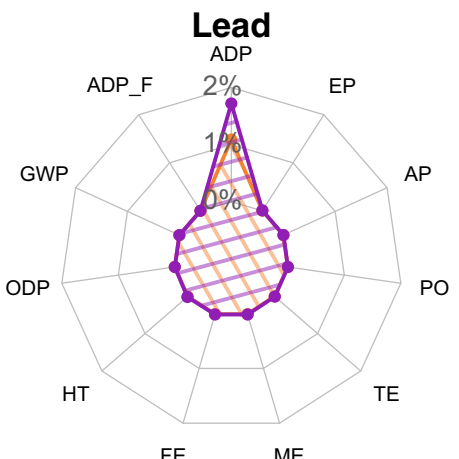

Steel

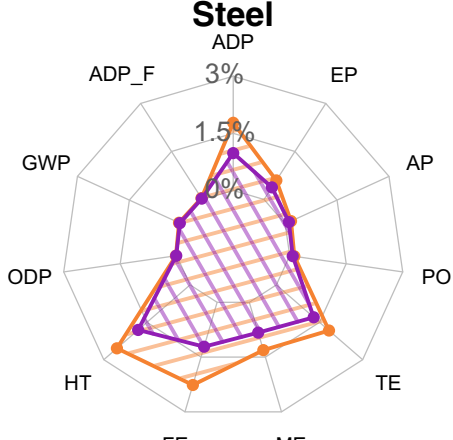

FE

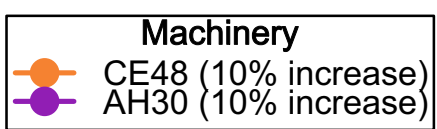

Fig. 3 Sensitivity analysis of the developed system to changes

et al. 2012a, b), this study indicates that this is not necessarily the case. This highlights the importance of up-todate LCA databases, which have higher resolutions for capturing potential impacts (Steubing et al. 2016). Impacts during this phase were, to a very large extent, linked to the assumed treatment of used tires at the end of their life. However, if this assumption was changed, and a cleaner alternative treatment was applied, the impact share from the treatment of used tires during the endof-life phase would decrease.

The sensitivity analysis focused on few impactful materials but did not consider sensitivity to the lifetimes of machinery. In other words, changes in the operable lifetime of machinery might substantially change the overall patterns shown in Fig. 2. This may conflict with the general statement that "the heavier the machinery, the higher the impacts," as a longer lifetime will equate to additional fuel consumption, additional maintenance and services, and additional waste materials. This longer lifetime may also affect the engine deterioration factor, that machinery will potentially be operated with a higher emission factor than suggested in Table 4.

The uncertainty analysis shows that the distribution of uncertainty becomes wider for machinery with higher relative impacts (see Fig. 2), which in turn results in stretching the density distribution, i.e., shallower probability density functions for machinery with relatively higher impacts. This, in fact, was the result of assuming an equal number of iterations (1000) for all types of machinery, and the same uncertainty values for all inputs and outputs to all phases, expect the operation phase.

\subsection{Effective hour}

Different types of machinery have engines with certain emission standards and are operated with different workloads (i.e., working cycles and operational hours). In addition, as construction machinery is operated for diverse purposes (e.g., material procurement/delivery or on-site construction), performance is influenced by several parameters. Some of these parameters might change fuel consumption rates and, subsequently, change the stated maximum permissible emissions (Armas et al. 2009; Sennoune et al. 2014).

Use of the "effective hour" (a function of lifetime and fuel efficiency) assisted in reducing uncertainties surrounding the operation time and the number of years a machine might be serviceable (Lindgren 2007; Notter and Schmied 2015). In addition, this unit indicates the number of hours a machine can be operated effectively, excluding unproductive hours. In other words, the effective hours unit only considers the total number of working hours minus inactive hours, for the total lifetime of a machine.

\subsection{Engine deterioration model}

In general, chemical reactions during the operation of an engine are challenging processes to represent. Even though 


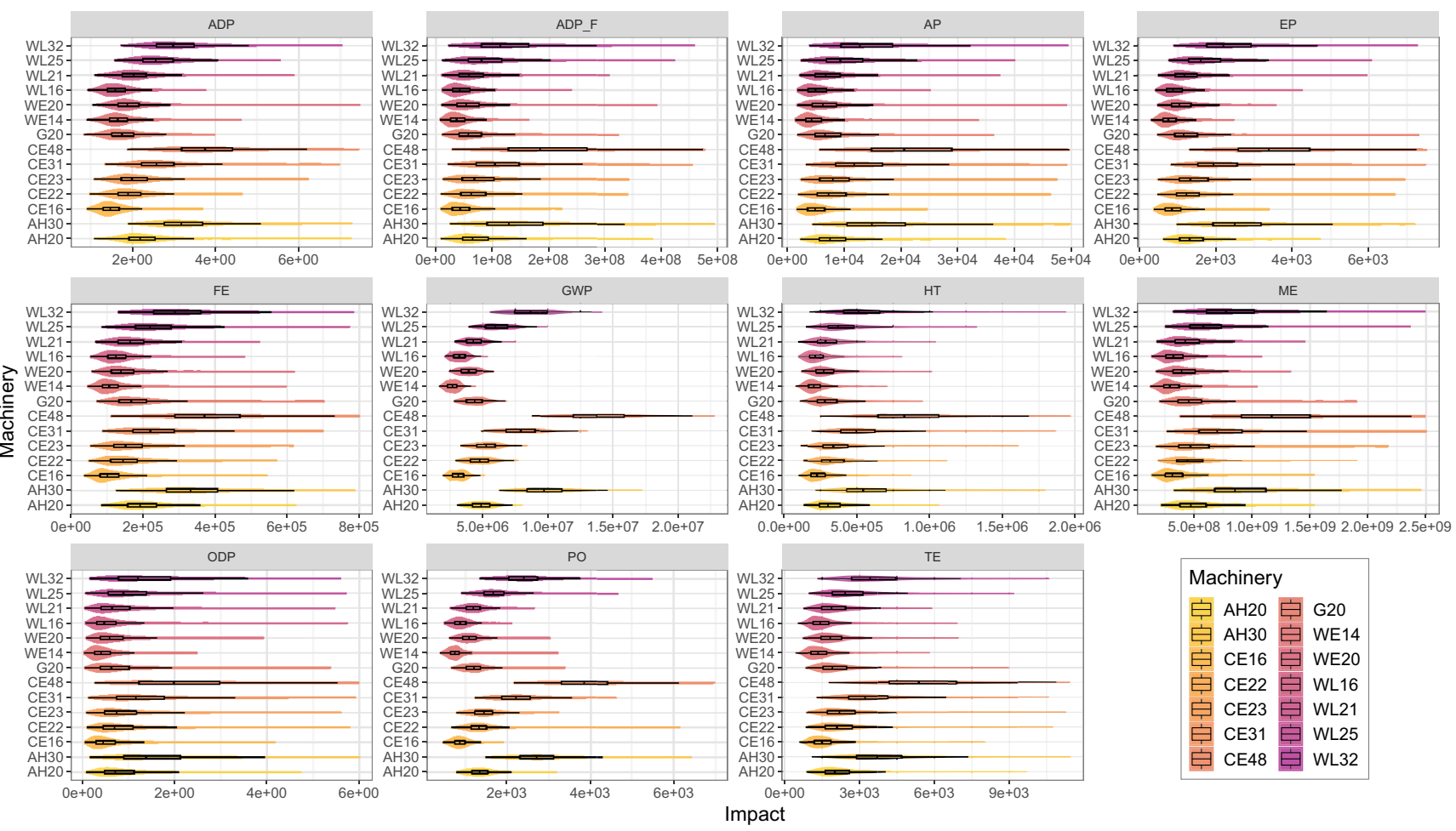

Fig. 4 Results of Monte Carlo simulation

pollutants form from carbonization of fuels within the combustion chamber, their formation heavily depends on the properties of the involved chemical compounds, their chemistry, and the conditions under which the reactions are occurring. Therefore, each pollutant from a given chemical reaction follows a particular pathway to its formation. Consequently, different pollutants are formed at different stages of the reaction and at different rates, and therefore might follow different deterioration models (Riemersma et al. 2002; Dallmann and Menon 2016; Thiruvengadam et al. 2016).

Use of deterioration rates based on logistic distribution models provided an alternative approach to the use of linear models used in prior work (Hajji and Lewis 2013; Notter and Schmied 2015). Such a simplified deterioration model might prove inadequate for representing real-world processes. For example, Pang et al. (2014), Borken-Kleefeld and Chen (2014), Ercan et al. (2015), and Zhang et al. (2017) showed that engine deterioration and pollutant formation does not propagate linearly. Nevertheless, to the best of our knowledge, there are no alternative distribution models recommended for construction machinery that adequately explain the effect of engine deterioration on the rate of pollutant formation over time. Therefore, there is some uncertainty whether the logistic distribution models applied in this study accurately describe the nature of engine deterioration over the lifetimes of different machinery.

\subsection{Applied impact assessment method}

The European Commission has issued various emission standards for different engines, which were distinctive in their performance and emission levels (Nesbit et al. 2016). Despite the historical regulations, the effect of different emission standards on relative environmental impact was not assessed in this study. However, by evaluating the emission factors in the EMEP/EEA guidebook, and by checking the characterization factors using the CML method, it became clear that only three of the impact categories could be influenced by different emission standards: acidification potential (AP), eutrophication potential (EP), and human toxicity (HT). This is because of NOx, which was the only critical airborne substance that could have affected the LCA results when considering different emission standards. However, this is only valid if the effect of technological advancements in fuel efficiency and after-treatment systems is disregarded, and if it is assumed that these are not influenced by the emission standard technologies, which affect the amount of pollution formation.

Across the studied subcategories of construction machinery, the causes of impacts in all impact categories derived from similar processes and polluting substances. This was a result of the machinery having similar powertrain technologies and being certified by the emission standard Stage V. However, it was found that the applied impact assessment method was limited in some respects. For example, the CML method was incapable of 
addressing the impacts associated with volatile organic compounds (VOCs) and PM. Hence, these airborne emissions were not considered by this method.

One of the main challenges with construction machinery, particularly when equipped with diesel-powered engines, is the high emission of PM throughout its service life (Lewis et al. 2009; Fu et al. 2012; Notter and Schmied 2015; Cao et al. 2016). Emission of PM has subsequent negative effects on human health, the acidity of water bodies, and nutrition balance of soils and ecosystems (Grantz et al. 2003; Kampa and Castanas 2008; Zhao et al. 2013; Gronlund et al. 2015; Kim et al. 2015). Similarly, VOCs have several negative impacts; VOCs have been found to have impacts on human health and the formation of tropospheric ozone (Lee et al. 2002; Koppmann 2007; Zhou et al. 2011; Costagliola et al. 2014).

\subsection{Comparison of results}

Even though the importance of construction machinery has been highlighted in the LCA community (Barandica et al. 2013; Garbarino et al. 2014; Barati and Shen 2016; Karlsson et al. 2017), very few studies were found that focus on the issue of the environmental impacts of construction machinery. Instead, the LCA of machinery has been integrated into bigger systems, like construction projects, in an effort to provide an overarching perspective on the potential impacts in the studied systems (Park et al. 2003; Cass and Mukherjee 2011; Barandica et al. 2013; Melanta et al. 2013; O'Born et al. 2014). In taking such an approach, it is difficult to directly compare existing results with this study. To overcome this, comparisons were performed based on the measured data reported in earlier studies during the operation phase of construction machinery. This, in a sense, helps understand the degree to which the inputs used in this study compare with previous work.

A review of the measured data reported in other studies showed that the amount of fuel consumption was 30 to $50 \%$ lower than that used in this study for machinery with a similar net power output (Lewis et al. 2012). Likewise, hourly measured emissions were lower than the calculated emissions in this study by factor of 3 to 10 (Lewis et al. 2012; Sennoune et al. 2014).

The higher values calculated in this study may potentially be linked to three major underlying factors. Firstly, this study considered a $100 \%$ load factor for each effective hour of operation. This unrealistic assumption might have drastically affected the results, producing higher emissions and associated impacts. However, the results may be adjusted for the operation phase, by simply applying relevant coefficients. This means that if, rather than $100 \%$, a load factor of $45 \%$ is more appropriate; the results for the operation phase can be multiplied by 0.45 to make the required adjustment.

Secondly, the effect of engine deterioration on the intensity of emissions was not evaluated in previous studies. This is due to an absence of continuous measurement data that reflect the effects of "wear and tear" during the accumulated engine hours. However, based on various studies (Chen and Borken-Kleefeld 2014; Pang et al. 2014; Ercan et al. 2015; Zhang et al. 2017), it has been proven that the rate of exhaust emission increases with hours of engine use. Thirdly, the assumed energy intensity and emission factors, coupled with the assumed engine deterioration model, might have resulted in higher calculated values for the operation phase.

\subsection{Limitations}

Even though it strived in this study to be critical and conduct a comprehensive study, there were still gaps left that this study could not close. Hence, it is advised to consider the presented results with caution. Below, some of the main challenges in this study could be found.

Due to a lack of available information, this study was unable to include some machine parts in the LCI processes including catalytic convertors, breaking systems, and filters; these components should be taken into account in future studies. Also, detailed information should replace generic information in the LCI datasets to enhance the quality of similar studies.

This study was unable to account for pollutants other than those documented in the EMEP/EEA guidebook, and it assumed a $100 \%$ load factor for each effective hour. In future studies, more pollutants should be included, and a more appropriate load factor should be applied. The engine deterioration model employed a logistic distribution to represent the effect of cumulative engine hours for all studied exhaust gases. This assumption might not hold, however, as pollution formation for different pollutants may follow different distributions. Moreover, the assumed energy intensity and emission factors per hourly consumed volume of diesel may have overestimated the cumulative emissions throughout the operation phase. Hence, it is necessary to apply representative energy intensity and emission factors, as well as engine deterioration models, to enhance the representativeness of LCA results.

This study assumed that all sulfur is converted to $\mathrm{SO} 2$ during the carbonization of fuel. This assumption may only hold in the absence of catalytic converters. However, all certified machinery has a catalytic converter (to perform desulfurization, DeSOx, and denitrogenating, DeNOx), meaning the amount of oxidized sulfur and nitrate is significantly reduced.

Although the applied emission factors were from the EMEP/EEA guidebook, which are based on laboratory testing (steady-state engine dynamometer tests), the accuracy of these factors needs to be improved for the future studies based on real-world measurements. Some recent research has emphasized the importance of using representative datasets, including those that reflect actual machinery duty cycles (Frey et al. 
2008; Lewis et al. 2009; Fu et al. 2012; Lijewski et al. 2013; Jerksjö et al. 2015; Cao et al. 2016). The importance of using more realistic emission factors was also emphasized by Lijewski et al. (2013), who found that emission of some pollutants based on different engine standards did not always reflect real-world measurements.

As it was shown by Lewis et al. (2012), changes in the operating condition for similar machinery affect the rate of fuel consumption. Even though the integration of EH to the functional unit in this study provided a potential way to explain the productive lifetime, it was not precise enough to attribute the specification of operating condition. Except for the wheel loaders that operated in well-designed and welloperated rock quarries to move blasted rock materials with a d50 of 200-250 mm, medium operating condition was considered for the rest of construction machinery. This limitation was due to the lack of more specified data that stopped this work from creating a more precise functional unit. However, there is a need for harmonization of LCA in the domain of civil work to ease the inclusivity of the LCA of construction machinery. And, this would be achievable by increasing the accuracy of the functional unit for construction machinery (like by introducing new guidelines) to assure the exclusivity of the LCA results.

This LCA study only considered the consumption of non-biogenic diesel fuel during the operation of the construction machinery. However, consumption of different fuel types, like biodiesel and natural gas, affects the LCA results because of variations in chemical compositions of each fuel, embodied environmental impacts, etc. Despite the evidence, it was very difficult to cover the matter in this study due to two main challenges. The first is related to the lack of existing information regarding EF corresponding to different fuel types, and the second is related to the lack of LCI processes for different fuel types in ecoinvent. This study used the publicly available data related to the EFs for non-road heavy-duty machinery that was published by EMEP/ EEA guidebook. The published document only showed EFs for diesel-based engines based on different engine emission standards, but it did not contain EF information for other fuel types.

Even if it could have been assumed that the EF is insignificant for biogenic and non-biogenic types of diesel, there was still a data gap in the used LCI database. Ecoinvent database unfortunately did not have LCI processes for different fuel types. Even though it would have been possible to combine ecoinvent with other LCI databases (e.g., US), it was decided not to do so. This was decided as the system boundary for different LCI databases often differs and combining different processes may result in double-counting.

\section{Conclusion}

The goal of this study was to perform a regionalized attributional LCA for different subcategories of construction machinery equipped with $\mathrm{Stage} \mathrm{V}$ diesel engines. The study used generic LCI processes developed by ecoinvent v3.3 and modified them to create related LCI processes. In addition, it used documented information about the statistical performance of different subcategories of construction machinery, and coupled this with meso-level emission accounting to quantify impacts through the entire machinery lifetime (i.e., a cradle-tograve assessment).

A similar conclusion is drawn to previous studies, that the operation phase of machinery is responsible for most impacts in the evaluated impact categories. The main cause of impacts from the operation phase stemmed from the production, distribution, and combustion of low-sulfur diesel, via tailpipe emissions. This was further demonstrated by the sensitivity analysis involving a partial increase in fuel consumption.

However, by performing the full lifecycle analysis of the studied construction machinery, it became clear that the operation phase was not the only cause of impacts. Utilization of non-energetic materials in the manufacturing and maintenance of machinery also contributed to the impact in some categories. In addition, the assumed recycling of tires at the end of their service life (as a fuel source for cement production) resulted in considerable impact on freshwater aquatic ecotoxicity (FE). This strategic approach towards material handling (at the end of its service life) may influence the realized impacts.

Additionally, it was shown that the environmental impacts and the relative differences between types of machinery followed approximately similar patterns. This might, to some degree, question the necessity of including so many indicators in the assessment; a machine with the highest impact in one was consistent with the impact in other categories. Such behaviors were sourced from similar influential factors and dependencies in the LCI processes, proportioned by the operation weight of machinery and, at the end, showed that heavier machinery had more environmental impacts across its entire lifecycle. However, this statement may not hold when evaluating the environmental impacts of machinery with different powertrain systems in future research. Yet, the impact results from different categories in this study may potentially be used for the future comparison.

Acknowledgments Open access funding provided by Chalmers University of Technology. The authors would like to thank Rolf André Bohne, Amund Bruland, Reyn O’Born, and Hrefna Run Vignisdottir for their fruitful discussion over the course of this paper.

Funding information This study was financially supported by the Norwegian Public Road Administration. 
Open Access This article is licensed under a Creative Commons Attribution 4.0 International License, which permits use, sharing, adaptation, distribution and reproduction in any medium or format, as long as you give appropriate credit to the original author(s) and the source, provide a link to the Creative Commons licence, and indicate if changes were made. The images or other third party material in this article are included in the article's Creative Commons licence, unless indicated otherwise in a credit line to the material. If material is not included in the article's Creative Commons licence and your intended use is not permitted by statutory regulation or exceeds the permitted use, you will need to obtain permission directly from the copyright holder. To view a copy of this licence, visit http://creativecommons.org/licenses/by/4.0/.

\section{References}

Abbasian-hosseini SA, Asce SM, Leming ML, Liu M (2016) Effects of idle tme restrictions on excess pollution from construction equipment 32:1-9. https://doi.org/10.1061/(ASCE)ME.1943-5479. 0000408

Ahn CR, Asce M, Lewis P, et al. (2013) Integrated framework for estimating, benchmarking, and monitoring pollutant emissions of construction operations. 139:1-11. https://doi.org/10.1061/(ASCE)CO. 1943-7862.0000755

Armas O, Lapuerta M, Mata C, Prez D (2009) Online emissions from a vibrating roller using an ethanol-diesel blend during a railway construction. Energy Fuel 23:2989-2996. https://doi.org/10.1021/ ef $900148 \mathrm{c}$

Athanassiadis D, Lidestav G, Nordfjell T (2002) Energy use and emissions due to the manufacture of a forwarder. Resour Conserv Recycl 34:149-160. https://doi.org/10.1016/S0921-3449(01)00100-8

Aune SE, Bruland A, Johannessen O (1992) Construction machinery cost calculations. Trondheim

Barandica JM, Fernández-Sánchez G, Berzosa Á, Delgado JA, Acosta FJ (2013) Applying life cycle thinking to reduce greenhouse gas emissions from road projects. J Clean Prod 57:79-91. https://doi.org/10. 1016/j.jclepro.2013.05.036

Barati K, Shen X (2016) Operational level emissions modelling of onroad construction equipment through field data analysis. Autom Constr 72:338-346. https://doi.org/10.1016/j.autcon.2016.08.010

Becken S, Patterson M (2009) Measuring national carbon dioxide emissions from tourism as a key step towards achieving sustainable tourism Measuring National Carbon Dioxide Emissions from Tourism as a Key Step Towards Achieving Sustainable Tourism 9582:. https://doi.org/10.2167/jost547.0, 14, 9338

Bruce DM, Hobson RN, Morgan CL, Child RD (2001) PM-power and machinery. J Agric Eng Res 80:343-350. https://doi.org/10.1006/ jaer.2001.0748

Cao T, Durbin TD, Russell RL, Cocker DR III, Scora G, Maldonado H, Johnson KC (2016) Evaluations of in-use emission factors from offroad construction equipment. Atmos Environ 147:234-245. https:// doi.org/10.1016/j.atmosenv.2016.09.042

Cass D, Mukherjee A (2011) Calculation of greenhouse gas emissions for highway construction operations by using a hybrid life-cycle assessment approach : case study for pavement operations. J Constr Eng Manag 137:1015-1025. https://doi.org/10.1061/(ASCE)CO.19437862.0000349

Caterpillar (2010) Operation and Maintenance Manual: motor grader

Caterpillar (2011) Operation and Maintenance Manual: excavator

Caterpillar (2012) Operation and Maintenance Manual: wheel loader

CEN/TC 350 (2011) SS-EN 15978:2011 Sustainability of construction works - assessment of environmental performance of buildings calculation method

Chen Y, Borken-Kleefeld J (2014) Real-driving emissions from cars and light commercial vehicles - results from 13 years remote sensing at
Zurich/CH. Atmos Environ 88:157-164. https://doi.org/10.1016/j. atmosenv.2014.01.040

Costagliola MA, Murena F, Prati MV (2014) Exhaust emissions of volatile organic compounds of powered two-wheelers: effect of cold start and vehicle speed. Contribution to greenhouse effect and tropospheric ozone formation. Sci Total Environ 468-469:1043-1049. https://doi.org/10.1016/j.scitotenv.2013.09.025

Dallmann T, Menon A (2016) Technology pathway for diesel engines used in non-road vehicles and equipment. Washington DC

Johan Deere (2012) Operation and Maintenance Manual: articulated dump truck

Doka G (2009) Life cycle inventory of the disposal of lignite spoil, coal spoil and coal tailings

EC (1997) DIRECTIVE 97/68/EC

EC (2002) DIRECTIVE 2002/88/EC

EC (2010) DIRECTIVE 2010/26/EU

ecoinvent (2016) ecoinvent. http://www.ecoinvent.org/about/about.html

Ercan T, Zhao Y, Tatari O, Pazour JA (2015) Optimization of transit bus fl eet' $\mathrm{s}$ life cycle assessment impacts with alternative fuel options. Energy 93:323-334. https://doi.org/10.1016/j.energy.2015.09.018

European Commission (2009) Directive 2009/30/EC oF The European Parliament and of the Council

Fan H (2017) A critical review and analysis of construction equipment emission factors. Procedia Eng 196:351-358. https://doi.org/10. 1016/j.proeng.2017.07.210

Frey HC, Rasdorf W, Kim K, et al. (2008) Comparison of real-world emissions of B20 biodiesel versus petroleum diesel for selected IMonroad vehicles and engine tiers. Transp Res Rec 33-42. https://doi.org/10.3141/2058-05

Fridstr L (2013) Norwegian transport towards the two-degree target: two scenarios. Oslo

Fu M, Ge Y, Tan J, Zeng T, Liang B (2012) Characteristics of typical non-road machinery emissions in China by using portable emission measurement system. Sci Total Environ 437:255-261. https://doi. org/10.1016/j.scitotenv.2012.07.095

Garbarino E, Rodriguez Quintero R, Donatello S, Wolf O (2014) Revision of green public procurement criteria for design , construction and maintenance of roads - technical report

Grantz DA, Garner JHB, Johnson DW (2003) Ecological effects of particulate matter. Environ Int 29:213-239. https://doi.org/10.1016/ S0160-4120(02)00181-2

Gronlund CJ, Humbert S, Shaked S, O’Neill MS, Jolliet O (2015) Characterizing the burden of disease of particulate matter for life cycle impact assessment. Air Qual Atmos Health 8:29-46. https:// doi.org/10.1007/s11869-014-0283-6

Guan D, Liu Z, Geng Y, Lindner S, Hubacek K (2012) The gigatonne gap in China' $s$ carbon dioxide inventories. Nat Clim Chang 2:672-675. https://doi.org/10.1038/nclimate1560

Hajji AM, Lewis P (2013) Development of productivity- based estimating tool for energy and air emissions from earthwork construction activities. Smart Sustain Built Environ 2:84-100. https://doi.org/10. 1108/20466091311325863

Helms H (Ifeu), Lambrecht U (Ifeu) (2009) The relevance of emissions from non-road mobile machinery in comparison with road transport emissions

Jerksjö M, Wisell T, Fridell E (2015) Non-road mobile machinery model - updates 2015

Kampa M, Castanas E (2008) Human health effects of air pollution. Environ Pollut 151:362-367. https://doi.org/10.1016/j.envpol. 2007.06.012

Karlsson CSJ, Miliutenko S, Björklund A, Mörtberg U, Olofsson B, Toller S (2017) Life cycle assessment in road infrastructure planning using spatial geological data. Int J Life Cycle Assess 22:1302-1317. https://doi.org/10.1007/s11367-016-1241-3 
Kasibhatla P, Arellano A, Logan JA, et al. (2002) Top-down estimate of a large source of atmospheric carbon monoxide associated with fuel combustion in Asia 29:1-4. https://doi.org/10.1029/2002GL015581

Kim H, Kwak M, Kim L, et al. (2012a) Life cycle assessment of complex heavy duty equipment. In: Sustainable design and manufacturing. ASME

Kim HM, Kwak M, Kim L, et al. (2012b) Comparative life cycle assessment of complex heavy-duty off-road equipment. In: 17th Design for Manufacturing and the Life Cycle Conference. ASME

Kim KH, Kabir E, Kabir S (2015) A review on the human health impact of airborne particulate matter. Environ Int 74:136-143. https://doi. org/10.1016/j.envint.2014.10.005

Koppmann R (2007) Volatile organic compounds in the atmosphere. Blackwell Publishing Ltd, Oxford

Krömer S, Kreipe E, Reichenbach D, Stark R (1999) Life cycle assessment of a car tyre

Lee J, Cho H, Choi B, et al. (2000) Life cycle assessment of tractors. Int J Life Cycle Assess 5:205-208. http:!/dx.Doi.oroJ1 0.1065/ Ica2000.02.018

Lee SC, Chiu MY, Ho KF, Zou SC, Wang X (2002) Volatile organic compounds (VOCs) in urban atmosphere of Hong Kong. Chemosphere 48:375-382. https://doi.org/10.1016/S00456535(02)00040-1

Lewis P, Rasdorf W (2017) Fuel use and pollutant emissions taxonomy for heavy duty diesel construction equipment. J Manag Eng 33: 04016038. https://doi.org/10.1061/(ASCE)ME.1943-5479. 0000484

Lewis P, Rasdorf W, Frey HC, Pang SH, Kim K (2009) Requirements and incentives for reducing construction vehicle emissions and comparison of nonroad diesel engine emissions data sources. J Constr Eng Manag 135:341-351. https://doi.org/10.1061/(ASCE)CO. 1943-7862.0000008

Lewis P, Leming M, Rasdorf W (2012) Impact of engine idling on fuel use and emissions of nonroad diesel construction equipment. $\mathrm{J}$ Manag Eng 28:31-38. https://doi.org/10.1061/(ASCE)ME.19435479.0000068

Lewis P, Ph D, Rasdorf W, Ph D (2017) Fuel use and pollutant emissions taxonomy for heavy duty diesel construction equipment. 33:1-8. https://doi.org/10.1061/(ASCE)ME.1943-5479.0000484

Lijewski P, Merkisz J, Fuc P, Kozak M, Rymaniak L (2013) Air pollution by the exhaust emissions from construction machinery under actual operating conditions. Appl Mech Mater 390:313-319. https://doi. org/10.4028/www.scientific.net/AMM.390.313

Lindgren M (2005) A transient fuel consumption model for non-road mobile machinery. Biosyst Eng 91:139-147. https://doi.org/10. 1016/j.biosystemseng.2005.03.011

Lindgren M (2007) A methodology for estimating annual fuel consumption and emissions from non-road mobile machinery - annual emissions from the non-road mobile machinery sector in Sweden for year 2006. Uppsala

Melanta S, Miller-Hooks E, Avetisyan HG (2013) Carbon footprint estimation tool for transportation construction projects. J Constr Eng Manag 139:547-555. https://doi.org/10.1061/(ASCE)CO.19437862.0000598

Nesbit M, Fergusson M, Colsa A, et al. (2016) Comparative study on the differences between the EU and US legislation on emissions in the automotive sector

Notter B, Schmied M (2015) Non-road fuel consumption and pollutant emissions and pollutant emissions

NTNU, MEF (2016) Construction machinery index

O’Born R, Brattebø H, OMK I et al (2014) Quantifying energy demand and greenhouse gas emissions of road infrastructure projects: an LCA case study of the Oslo fjord crossing in Norway. 2010:445446

Pang Y, Fuentes M, Rieger P (2014) Trends in the emissions of volatile organic compounds (VOCs) from light-duty gasoline vehicles tested on chassis dynamometers in Southern California. Atmos Environ 83:127-135. https://doi.org/10.1016/j.atmosenv.2013.11.002

Park K, Hwang Y, Seo S, Seo H (2003) Quantitative assessment of environmental impacts on life cycle of highways. J Constr Eng Manag 129:25-31. https://doi.org/10.1061/(ASCE)07339364(2003)129:1(25)

Pre' (2018) SimaPro Database Manual: methods library

Rasdorf W, Frey C, Lewis P, Kim K, Pang SH, Abolhassani S (2010) Field procedures for real-world measurements of emissions from diesel construction vehicles. J Infrastruct Syst 16:216-225. https:// doi.org/10.1061/(ASCE)IS.1943-555X.0000027

Riemersma I, Hendriksen P, Burgwal E van de, Verlaak J (2002) Emission control technology for heavy-duty vehicles

Sennoune M, Muresan B, Capony A, et al. (2014) In situ evaluation of earthwork machinery emissions. 1-8

SimaPro (2017) What's new in SimaPro 8.4? https://simapro.com/2017/ new-in-simapro-8-4/

Smith SD, Wood GS, Gould M (2000) A new earthworks estimating methodology. Constr Manag Econ 18:219-228. https://doi.org/10. 1080/014461900370843

Steubing B, Wernet G, Reinhard J, Bauer C, Moreno-Ruiz E (2016) The ecoinvent database version 3 (part II): analyzing LCA results and comparison to version 2. Int J Life Cycle Assess 3:1-13. https://doi. org/10.1007/s11367-016-1109-6

Thiruvengadam A, Besch M, Carder D, Oshinuga A, Pasek R, Hogo H, Gautam M (2016) Unregulated greenhouse gas and ammonia emissions from current technology heavy-duty vehicles. J Air Waste Manage Assoc 66:1045-1060. https://doi.org/10.1080/10962247. 2016.1158751

UNEP (2011) Technical guidelines for the environmentally sound management of used and waste pneumatic tyres

Volvoce (2018) Volvo construction equipment: environmental product declarations. www.volvoce.com

Weber C, Amundsen AH (2016) Emission from vehicles with Euro 6 / VI technology . Results from the measurement program in EMIROAD 2015. Oslo

Weidema BP, Bauer C, Hischier R, et al. (2013) Overview and methodology: data quality guideline for the ecoinvent database version 3

Wernet G, Bauer C, Steubing B, Reinhard J, Moreno-Ruiz E, Weidema B (2016) The ecoinvent database version 3 (part I): overview and methodology. Int J Life Cycle Assess 3:1-13. https://doi.org/10. 1007/s11367-016-1087-8

Wetterberg C, Magnusson R, Lindgren M, Åström S (2007) Engine exhaust gas emissions from non-road mobile machinery equipped with diesel engines. Uppsala

Winther M, Samaras Z, Zierock K-H, Lambrecht U (2013) EMEP/EEA emission inventory guidebook 2013

Winther M, Dore C, Lambrecht U, et al. (2017) EMEP/EEA air pollutant emission inventory guidebook 2016

Zhang Q, Fan J, Yang W, Chen B, Zhang L, Liu J, Wang J, Zhou C, Chen $X$ (2017) The effects of deterioration and technological levels on pollutant emission factors for gasoline light-duty trucks. J Air Waste Manage Assoc 67:814-823. https://doi.org/10.1080/10962247. 2017.1301275

Zhao B, Wang S, Dong X, Wang J, Duan L, Fu X, Hao J, Fu J (2013) Environmental effects of the recent emission changes in China: implications for particulate matter pollution and soil acidification. Environ Res Lett 8. https://doi.org/10.1088/1748-9326/8/2/024031

Zhou J, You Y, Bai Z, Hu Y, Zhang J, Zhang N (2011) Health risk assessment of personal inhalation exposure to volatile organic compounds in Tianjin, China. Sci Total Environ 409:452-459. https:// doi.org/10.1016/j.scitotenv.2010.10.022

Publisher's note Springer Nature remains neutral with regard to jurisdictional claims in published maps and institutional affiliations. 